\title{
出力微分情報を用いた双線形システムの状態観測器 ${ }^{\dagger}$
}

\author{
舟橋 康, 行*. 安 達 由 洋* \\ State Observer for Bilinear Systems Using Derivative of Output
}

Yasuyuki Funahashi* and Yoshihiro AdACHI*

From the viewpoint of state estimation, we may regard bilinear systems as time-varying systems and apply to them the results with the observer of a linear time-varying system. However, since the input is in general not known a priori, it seems impossible to apply the theories of time-varying linear systems to bilinear systems. For the purpose of simple implementation, a new type of state observer is proposed in this paper.

The output of the bilinear system is one-time differentiable. Based on this fact and on the concept of Lyapunov stability, we propose a method for designing a state observer for bilinear systems, using information on the input, output and one-time deriverative of the output. This state observer has a specific feature of simple structure and the norm of the estimation error converges to zero asymptotically irrespective of the input. As a result, state observers are shown to be designed for a wider class of bilinear 'systems. Also the condition, under which a state observer without information on one-time derivative can be designed, is given obviously.

\section{1. 緒 言}

本論文では，入出力および出力の 1 階微分情報を用 いた双線形システムの状態観測器の構成法について報 告する.

状態推定の立場からは, 双線形システムを線形時変 システムとみなして，線形時変システムの観測器に対 する結果（たとえば 1)）を適用するととが考えられ る.しかし，この場合入力をパラメータとして含む複 雑な行列方程式を解かねばならない，しかも，一般に

$\uparrow$ US-Japan Cooporation Research の St. Louis Meeting で発表 (昭 $52 \cdot 8$ )

* 名古屋大学工学部 名古屋市千種区不老町

* Faculty of Engineering, Nagoya University, Nagoya (Received February 1, 1978)
は入力はあらかじめわからないので，オンラインで行 列方程式を解かねばならず，現実には適用不可能と考 えられる. そこで, 比較的簡単に構成できる双線形シ ステムの状態観測器についての研究がいくつか報告さ れている2) 8). たとえば，文献 3)，4）では推定誤差が 入力に依存しない観测器が与えられた。また，推定誤 差が入力に依存することは許し，単に推定誤差のノル ムが入力に関係なく漸近的に零に收束する観測器を考 えれば，文献 3)，4).よりも広いクラスのシステムに対 して状態観測器が構成できることが示された7).なお, とれらは入力および出力の情報のみを用いた観測器で ある。

双線形システムの出力は常に 1 階微分可能である. この事実から，入出力および出力の 1 階微分の情報を 用いた新たな観測器が構成されている8).

本論文では，入出力执よび出力の 1 階微分の情報を 用いた双線形システムの観測器を，リアプノフの安定 性の観点から構成するととを考える. その結果，本方 法によれば従来の方法で構成できないクラスのシステ ムに対しても観測器が構成できるととになった。 まず 2 節で観測器の定義を行い，3 節では観測器の存在条 件を導き，その構成法を与える。また，特別な場合に は出力の 1 階微分情報を用いない観測器に変換できる ことを示す. 最後に，4節ではいくつかのシステムに 対して実際に観測器を構成し，本論文の方法がこれま でのものより広いクラスのシステムに適用できるとと を示す.

\section{2. 状態観測器の基本式}

つぎのような双線形システム $\Sigma\left(A_{i}, B, C\right)$ を考え る.

$$
\begin{aligned}
\Sigma: \dot{x} & =\left(A_{0}+\sum_{i=1}^{m} u_{i} A_{i}\right) x+B u \\
y & =C x
\end{aligned}
$$

ただし， $x$ は $n$ 次元状態ベクトル, $u=\left[u_{1}, u_{2}, \cdots, u_{m}\right]^{T}$ は $m$ 次元入力ベクトル, $y$ は $p$ 次元出力ベクトルであ 
り， $A_{i}(i=0,1, \cdots, m), B, C$ はそれぞれ適当なサイ ズの実定数行列である. また, $\operatorname{rank} C=p$ とする. 乙 こで，つぎの (2.2)式を満たす任意の $(n-p) \times n$ 行列 $D$ をとり， $T=\left[C^{T} D^{T}\right]^{T}$ で状態空間の基底変換を行 j.

$$
\operatorname{rank}\left[\begin{array}{l}
C \\
D
\end{array}\right]=n
$$

そのとき，行列 $A_{i}, B, C$ はそれぞれつぎの行列 $\bar{A}_{i}$, $\bar{B}, \bar{C}$ 亿変換される.

$$
\begin{aligned}
& \bar{A}_{i}=T A_{i} T^{-1}=\left[\begin{array}{ll}
\bar{A}_{i 11} & \bar{A}_{i 12} \\
\bar{A}_{i 21} & \bar{A}_{i 22}
\end{array}\right] \quad i=0,1, \cdots, m \\
& \bar{B}=T B=\left[\begin{array}{l}
\bar{B}_{1} \\
\bar{B}_{2}
\end{array}\right] \\
& \bar{C}=C T^{-1}=\left[\begin{array}{ll}
I_{p} & 0
\end{array}\right]
\end{aligned}
$$

ただし, $\bar{A}_{i 11} \in \boldsymbol{R}^{p \times p}, \quad \bar{A}_{i 12} \in \boldsymbol{R}^{p \times(n-p)}, \quad \bar{A}_{i 21} \in \boldsymbol{R}^{(n-p) \times p}$, $\bar{A}_{i 22} \in \boldsymbol{R}^{(n-p) \times(n-p)}, \quad \bar{B}_{1} \in \boldsymbol{R}^{p \times m}, \bar{B}_{2} \in \boldsymbol{R}^{(n-p) \times m}$ の実定 数行列であり， $I_{p}$ は $p$ 次の単位行列である. また, つ ぎのように状態ベクトルを分割する.

$$
\bar{x}=T x=\left[\begin{array}{l}
\bar{x}_{1} \\
\bar{x}_{2}
\end{array}\right]
$$

ただし， $\bar{x}_{1} \in \boldsymbol{R}^{p}, \bar{x}_{2} \in \boldsymbol{R}^{n-p}$ である.

このとき, 変換された双線形システム $\Sigma^{\prime}$ はつぎの ように記述される。

$$
\begin{aligned}
\Sigma^{\prime}:\left[\begin{array}{c}
\dot{\bar{x}}_{1} \\
\dot{\bar{x}}_{2}
\end{array}\right]= & {\left[\begin{array}{ll}
\bar{A}_{011} & \bar{A}_{012} \\
\bar{A}_{021} & \bar{A}_{022}
\end{array}\right]\left[\begin{array}{l}
\bar{x}_{1} \\
\bar{x}_{2}
\end{array}\right] } \\
& +\sum_{i=1}^{m} u_{i}\left[\begin{array}{ll}
\bar{A}_{i 11} & \bar{A}_{i 12} \\
\bar{A}_{i 21} & \bar{A}_{i 22}
\end{array}\right]\left[\begin{array}{l}
\bar{x}_{1} \\
\bar{x}_{2}
\end{array}\right]+\left[\begin{array}{l}
\bar{B}_{1} \\
\bar{B}_{2}
\end{array}\right] u \\
y= & {\left[\begin{array}{ll}
I_{p} & 0
\end{array}\right]\left[\begin{array}{l}
\bar{x}_{1} \\
\bar{x}_{2}
\end{array}\right] }
\end{aligned}
$$

第 2 式より $\bar{x}_{1}=y$ である. したがって $\bar{x}_{1}$ は直接に観 測できるので $\bar{x}_{2}$ を推定すればよい， $\bar{x}_{2}$ に対する方程 式を取り出すと次式になる.

$$
\begin{aligned}
\dot{\bar{x}}_{2}= & \left(\bar{A}_{022}+\sum_{i=1}^{m} u_{i} \bar{A}_{i 22}\right) \bar{x}_{2} \\
& +\left(\bar{A}_{021}+\sum_{i=1}^{m} u_{i} \bar{A}_{i 21}\right) y+\bar{B}_{2} u
\end{aligned}
$$

また， $\bar{x}_{2}$ に対する観測方程式はつぎのようになる.

$$
\begin{aligned}
\eta & =\dot{y}-\left(\bar{A}_{011}+\sum_{i=1}^{m} u_{i} \bar{A}_{i 11}\right) y-\bar{B}_{1} u \\
& =\left(\bar{A}_{012}+\sum_{i=1}^{m} u_{i} \bar{A}_{i 12}\right) \bar{x}_{2}
\end{aligned}
$$

そこで, システム $\Sigma^{\prime}$ に対してつぎのシステム $\Sigma_{0}$ を 考える.

$$
\begin{aligned}
\Sigma_{0}: \dot{z}= & \left(\bar{A}_{022}+\sum_{i=1}^{m} u_{i} \bar{A}_{i 22}\right) z \\
& +\left(\bar{A}_{021}+\sum_{i=1}^{m} u_{i} \bar{A}_{i 21}\right) y+\bar{B}_{2} u
\end{aligned}
$$

$$
+\left(K_{0}+\sum_{i=1}^{m} u_{i} K_{i}\right)\left[\eta-\left(\bar{A}_{012}+\sum_{i=1}^{m} u_{i} \bar{A}_{i 12}\right) z\right]
$$

ただし， $z$ は $(n-p)$ 次元ベクトルであり， $K_{i} \in$ $\boldsymbol{R}^{(n-p) \times(n-p)}(i=0,1, \cdots, m)$ である.

\section{【定義 1】}

$\Sigma^{\prime}$ と $\Sigma_{0}$ の間に, 初期状態 $x(0), z(0)$ および入力 $u(\cdot)$ に関係なく

$$
\lim _{t \rightarrow \infty}\left[\bar{x}_{2}(t)-z(t)\right]=0
$$

が成立するとき， $\Sigma_{0}$ を $\Sigma^{\prime}$ の状態観測器という。

ここで, $e=\bar{x}_{2}-z$ と定義すれば， $e$ はつぎの方程 式を満たす。

$$
\begin{aligned}
\dot{e}= & {\left[\bar{A}_{022}+\sum_{i=1}^{m} u_{i} \bar{A}_{i 22}\right.} \\
& \left.-\left(K_{0}+\sum_{i=1}^{m} u_{i} K_{i}\right)\left(\bar{A}_{012}+\sum_{i=1}^{m} u_{i} \bar{A}_{i 12}\right)\right] e \\
= & {\left[\left(\bar{A}_{022}-K_{0} \bar{A}_{012}\right)\right.} \\
& +\sum_{i=1}^{m} u_{i}\left(A_{i 22}-K_{i} \bar{A}_{012}-K_{0} \bar{A}_{i 12}\right) \\
& \left.-\sum_{i=1}^{m} \sum_{j=1}^{m} u_{i} u_{j} K_{i} \bar{A}_{j 12}\right] e
\end{aligned}
$$

誤差 $e$ 自身が入力 $u(\cdot)$ に依存しないことを要求すれ ば，つぎの定理が得られる.

\section{《定理 $\mathbf{1}^{8)} 》$}

$\Sigma_{0}$ が $\Sigma^{\prime}$ の状態観測器であるための十分条件は, つぎの条件 $(\mathrm{i}) \sim($ iii $)$ を満たす $K_{0}, K_{i}(i=1,2, \cdots, m)$ が存在することである.

(i) $\bar{A}_{022}-K_{0} \bar{A}_{012}$ : 安定

(ii) $\quad \bar{A}_{i 22}-K_{i} \bar{A}_{012}-K_{0} \bar{A}_{i 12}=0 \quad i=1,2, \cdots, m$

(iii) $K_{i} \bar{A}_{j 12}=0 \quad i, j=1,2, \cdots, m$

\section{3. 安定な状態観測器の構成}

前節では, 観測器を定義し 観測詔差が入力 $u(\cdot)$ に 依存しない之いう制約により観測器の存在条件を求め た、しかしながら，上述の存在条件を満たさないシス テムむ数多く存在する. そこで, この節では，リアプ ノフの安定性の考えを用いて，よりゆるやかな条件の あとで観測器を構成することを考える.

\section{《定理 2》}

$\Sigma_{0}$ が $\Sigma^{\prime}$ の状態観測器であるための十分条件は, つぎの条件を満たす $K_{0}, K_{i}(i=1,2, \cdots, m)$ および正 定対称行列 $P, Q$ が存在することである.

(i ) $P\left(\bar{A}_{022}-K_{0} \bar{A}_{012}\right)+\left(\bar{A}_{022}-K_{0} \bar{A}_{012}\right)^{T} P=-Q$ 
(ii) $P\left(\bar{A}_{i 22}-K_{i} \bar{A}_{012}-K_{0} \bar{A}_{i 12}\right)$

$+\left(\bar{A}_{i 22}-K_{i} \bar{A}_{012}-K_{0} \bar{A}_{i 12}\right)^{T} P=0$ $i=1,2, \cdots, m$

(iii) $P\left(K_{i} \bar{A}_{j 12}\right)+\left(K_{i} \dot{A}_{j 12}\right)^{T} P$

$$
=0 \quad i, j=1,2, \cdots, m
$$

(証明)

$V(e)=e^{T} P e$ とする．乙こで $V(e)$ の時間微分をと 万と

$$
\begin{aligned}
\frac{d}{d t} V(e)= & \dot{e}^{T} P e+e^{T} P \dot{e} \\
= & e^{T}\left[P\left(\bar{A}_{022}-K_{0} \bar{A}_{012}\right)\right. \\
& \left.+\left(\bar{A}_{022}-K_{0} \bar{A}_{012}\right)^{T} P\right] e \\
& +\sum_{i=1}^{m} u_{i} e^{T}\left[P\left(\bar{A}_{i 22}-K_{i} \bar{A}_{012}-K_{0} \bar{A}_{i 12}\right)\right. \\
& \left.+\left(\bar{A}_{i 22}-K_{i} \bar{A}_{012}-K_{0} \bar{A}_{i 12}\right)^{T} P\right] e \\
& -\sum_{i=1}^{m} \sum_{j=1}^{m} u_{i} u_{j} e^{T}\left[P\left(K_{i} \bar{A}_{j 12}\right)\right. \\
& \left.+\left(K_{i} \bar{A}_{j 12}\right)^{T} P\right] e
\end{aligned}
$$

条件 ( i ) （亚)を満足するような $K_{0}, K_{i}(i=1,2, \cdots$, $m), P$ が存在すると仮定すれば，その $K_{0}, K_{i}, P$ に対

$$
\begin{aligned}
\frac{d}{d t} V(e)= & e^{T}\left[P\left(\bar{A}_{022}-K_{0} \bar{A}_{012}\right)\right. \\
& \left.+\left(\bar{A}_{022}-K_{0} \bar{A}_{012}\right)^{T} P\right] e \\
= & -e^{T} Q e<0
\end{aligned}
$$

れたがって，(2.10)式はリアプノフ関数 $V(e)=e^{T} P e$ をむち, 任意の入力 $u(\cdot)$ に対して $e=0$ は大域的漸近 安定な平衡点となる，ゆえに，(2.8)式で表わされる システム $\Sigma_{0}$ に扔いて $K_{0}, K_{i}(i=1,2, \cdots, m)$ を条件 （ｉ）（ ｉii）を満足するように選べば， $\Sigma_{0}$ は $\Sigma^{\prime}$ の状 態観测器となる。

(証明終)

定理 2 で双線形システムに対する出力の 1 階微分の 情報を用いた観測器の存在条件を，リアプノフの安定 性の考えから導いた，すなわち，システム $\Sigma^{\prime} に$ 対し て定理 2 の条件 $(\mathrm{i}) \sim($ iil $)$ を満たす $K_{0}, K_{i}(i=1,2$, $\cdots, m), P, Q$ が存在するとき, パラメータ行列 $K_{0}$, $K_{i}(i=1,2, \cdots, m)$ の值をそのように選べば，システ $\Delta \Sigma_{0}$ 㹥推定誤差 $e$ のノルムが入力 $u(\cdot)$ および初期 状態 $\bar{x}_{2}(0), z(0)$ に無関係に漸近的に零に収束する. しかし，(2.10)式から明らかなように誤差 $e$ 自身は入 力依存している.

この観測器の収束速度に関しては，つぎの系が成立 する.

\section{[系 1]}

定理 2 の条件が成立するとき, 観測器の収束速度は 次式で評価される。

$$
\begin{gathered}
\left\|\bar{x}_{2}(t)-z(t)\right\| \leqq\left\|\bar{x}_{2}(0)-z(0)\right\| \sqrt{\frac{\lambda_{\max }(P)}{\lambda_{\min }(P)}} \\
\cdot \exp \left[-\frac{\lambda_{\min }(Q)}{2 \lambda_{\max }(P)} t\right]
\end{gathered}
$$

ここで, $\lambda_{\min }(P), \lambda_{\max }(P)$ はそれぞれ $P$ の最小固有值, 最大固有値を表わす。

(証明)

定理 2 の条件が成立していると仮定する. $V(e(t))=$ $e(t)^{T} P e(t)$ とすれば次式が成立する.

$$
\lambda_{\min }(P)\|e(t)\|^{2} \leqq V(e(t)) \leqq \lambda_{\max }(P)\|e(t)\|^{2}
$$

また（3.3)式より $d V(e(t)) / d t=-e(t)^{T} Q e(t)$ である 加ら

$$
-\lambda_{\max }(Q)\|e(t)\|^{2} \leqq \frac{d}{d t} V(e(t)) \leqq-\lambda_{\min }(Q)\|e(t)\|^{2}
$$

となる. (3.5), (3.6)式より次式が得られる.

$$
\frac{d}{d t} V(e(t)) \leqq-\frac{\lambda_{\min }(Q)}{\lambda_{\max }(P)} V(e(t))
$$

したがって，

$$
V(e(t)) \leqq V(e(0)) \exp \left[-\frac{\lambda_{\min }(Q)}{\lambda_{\max }(P)} t\right]
$$

ととる. (3.5)式と(3.8)式より(3.6)式が得られる.

定理 2 で構成された観測器は出力の微分值を用いて いる. 工学的見地からは微分值を避けることが望まし い. そこで以下には微分值を用いずに観測器が構成で きる場合を調べる.

いま, システム $\Sigma^{\prime}$ に対して $K_{i}=0(i=1,2, \cdots, m)$ として定理 2 の条件（i ）（㧫)を満たす $K_{0}, P, Q$ が 存在する場合を考える。このときシステム $\Sigma^{\prime}$ の観測 器 $\Sigma_{0}$ を $z^{*}=z-K_{0} y$ で状態変換すると,つぎのシス テム $\Sigma_{0}$ となる。

$$
\begin{aligned}
\Sigma_{0}^{*}: \dot{z}^{*}= & {\left[\bar{A}_{022}+\sum_{i=1}^{m} u_{i} \bar{A}_{i 22}\right.} \\
& \left.-K_{0}\left(\bar{A}_{012}+\sum_{i=1}^{m} u_{i} \bar{A}_{i 12}\right)\right] z^{*} \\
& +\left(\bar{A}_{022}+\sum_{i=1}^{m} u_{i} \bar{A}_{i 22}\right) K_{0} y \\
& -K_{0}\left(\bar{A}_{011}+\sum_{i=1}^{m} u_{i} \bar{A}_{i 11}\right) y \\
& -K_{0}\left(\bar{A}_{012}+\sum_{i=1}^{m} u_{i} \bar{A}_{i 12}\right) K_{0} y \\
& +\left(\bar{A}_{021}+\sum_{i=1}^{m} u_{i} \bar{A}_{i 21}\right) y+\bar{B}_{2} u-K_{0} \bar{B}_{1} u \\
w^{*}= & z^{*}+K_{0 y}
\end{aligned}
$$

ここで, $e^{*}=\bar{x}_{2}-w^{*}$ とおけば次式が成立する. 


$$
\begin{aligned}
\dot{e}^{*}= & {\left[\bar{A}_{022}+\sum_{i=1}^{m} u_{i} \bar{A}_{i 22}\right.} \\
& \left.-K_{0}\left(\bar{A}_{012}+\sum_{i=1}^{m} u_{i} \bar{A}_{i 12}\right)\right] e^{*}
\end{aligned}
$$

システム(3.9) は出力の微分の項を含まない.したが って，つぎの定理が成立する.

\section{《定理 3》}

システム $\Sigma^{\prime}$ に対して; $K_{i}=0(i=1,2, \cdots, m)$ とし て定理 2 の条件 $(\mathrm{i}) \sim\left(\right.$ III) 満たす行列 $K_{0}$ および正 定対称行列 $P, Q$ が存在すれば，出力の 1 階微分を含 まない観測器 $\Sigma_{0}$ * が構成できる：との観測器の収束 速度は

$$
\begin{aligned}
\left\|\bar{x}_{2}(t)-w^{*}(t)\right\| \leqq & \left\|\bar{x}_{2}(0)-w^{*}(0)\right\| \sqrt{\frac{\lambda_{\max }(P)}{\lambda_{\min }(P)}} \\
\cdot & \exp \left[-\frac{\lambda_{\min }(Q)}{2 \lambda_{\max }(P)} t\right]
\end{aligned}
$$

で評価される。

定理 3 で構成された観測器 $\Sigma_{0}$ *は，文献 7) で与え られた観測器と一致している。したがって，本論文の 構成法は文献 7) を特別な場合として含む。

$\bar{A}_{112}=0$ という条件を満たす限られた 1 入力双線形 システムに対して，文献 6) で観測器が提案されてい る。しかし， $K_{1}$ に相当する項が考慮されてなく，ま たリアプノフ関数，すなわち正定対称行列 $P, Q$ が入 力 $u(\cdot)$ に依存する時間関数にとられている。：之のた め大域的漸近安定な観測器の存在条件が入力 $u(\cdot)$ に 依存する. したがって, 入力関数 $u(\cdot)$ があらかじめ わかるか，または入力值 $u(t)$ がある種の条件を満た さなければ文献 6) による観測器は構成できない。な お, 文献 6) では大域的漸近安定な観測器を構成でき なかったシステムに対して，4節の例 3 ，例 4 におい て本論文の方法で観測器を構成する.

\section{4. 例 題}

この節では，定理 2 で得た観測器の存在条件が文献 7), 8) による観测器の存在条件よりゆるくなっている こと，したがって従来の方法よりも広いクラスのシス デムに対し観測器が構成可能であるととを例により示 す. 文献 8) の観測器の存在条件は定理 1 で与えられ ている. 文献 7) -ではつぎの条件

(i) $P\left(S \bar{A}_{012}+\bar{A}_{022}\right)+\left(S \bar{A}_{012}+\bar{A}_{022}\right)^{T} P=-Q$

(ii) $P\left(S \bar{A}_{i 12}+\bar{A}_{i 22}\right)+\left(S \bar{A}_{i 12}+\bar{A}_{i 22}\right)^{T} P=0$

$$
i=1,2, \cdots, m
$$

を満たす行列 $S$ および正定対称行列 $P, Q$ が存在する とき,シスデム $\Sigma^{\prime}$ の観測器が存在するとなっている.
まず，例 1 は従来の観測器の存在条件のいずれかを 満たさないシステムであり，例 2 はどの条件す一つ一 つは満たしうるが，全部を同時に満たすことはできな いシステムである.

[例 1]つぎのシステムを考える.

$$
\begin{aligned}
& \dot{x}(t)=\left[\begin{array}{r:rr}
a_{01} & 1 & 1 \\
\hdashline a_{02} & -1 & 0 \\
a_{03} & 0 & -1
\end{array}\right] x(t)+u(t)\left[\begin{array}{r:rr}
a_{11} & 0 & 0 \\
\hdashline a_{12} & 1 & 0 \\
a_{13} & 0 & -1
\end{array}\right] x(t) \\
& y(t)=\left[\begin{array}{lll}
1 & 0 & 0
\end{array}\right] x(t)
\end{aligned}
$$

このシステムは(2.5)式の形をしている.すなわち，

$\bar{A}_{012}=\left[\begin{array}{ll}1 & 1\end{array}\right], \quad \bar{A}_{112}=\left[\begin{array}{ll}0 & 0\end{array}\right]$

$$
\bar{A}_{022}=\left[\begin{array}{rr}
-1 & 0 \\
0 & -1
\end{array}\right], \quad \bar{A}_{122}=\left[\begin{array}{rr}
1 & 0 \\
0 & -1
\end{array}\right]
$$

である.このシステムに対して，まず文献 7) による 観测器を適用する. $\vec{A}_{112}=\left[\begin{array}{ll}0 & 0\end{array}\right]$ であるから $S$ の選択 に無関係に

$$
S \bar{A}_{112}+\bar{A}_{122}=\left[\begin{array}{rr}
1 & 0 \\
0 & -1
\end{array}\right]
$$

であるので，(4.2)式はつぎのようになる.

$$
P\left[\begin{array}{rr}
1 & 0 \\
0 & -1
\end{array}\right]+\left[\begin{array}{rr}
1 & 0 \\
0 & -1
\end{array}\right] P=0
$$

この (4.4)式を満たす正定対称行列 $P$ は存在しない. したがって文献 7) による観測器は構成不可能である。 つぎに文献 8) による観測器を適用してみよう.

$$
K_{0}=\left[\begin{array}{l}
k_{01} \\
k_{02}
\end{array}\right] \quad K_{1}=\left[\begin{array}{l}
k_{11} \\
k_{12}
\end{array}\right]
$$

とおけば，定理 1 の条件 (ii)はつぎのようになる.

$$
\bar{A}_{122}-K_{1} \bar{A}_{012}-K_{0} \bar{A}_{112}=\left[\begin{array}{cc}
1-k_{11} & -k_{11} \\
-k_{12} & -1-k_{12}
\end{array}\right]=0
$$

したがって $K_{0}, K_{1}$ をどのように選んでも(4. 6)式を満 たすととができないので，文献 8) による観測器す構 成不可能である. こてで本論文の観測器を適用する. まず， $\bar{A}_{112}=\left[\begin{array}{ll}0 & 0\end{array}\right]$ であるから $K_{1}$ に無関係に定理 2 の条件 (ii) は成立する. また $K_{0}, K_{1}$ を(4.5)式のよう におけば定理 2 の条件 ( i ), (ii) はつぎのようになる。

(i)

$$
\begin{aligned}
& P\left[\begin{array}{cc}
-1-k_{01} & -k_{01} \\
-k_{02} & -1-k_{02}
\end{array}\right] \\
& \quad+\left[\begin{array}{cc}
-1-k_{01} & -k_{02} \\
-k_{01} & -1-k_{02}
\end{array}\right] P=-Q
\end{aligned}
$$

(ii)

$$
\begin{aligned}
& P\left[\begin{array}{cc}
1-k_{11} & -k_{11} \\
-k_{12} & -1-k_{12}
\end{array}\right] \\
& \quad+\left[\begin{array}{cc}
1-k_{11} & -k_{12} \\
-k_{11} & -1-k_{12}
\end{array}\right] P=0
\end{aligned}
$$

この(4.7)，(4.8)式を満たす $K_{0}, K_{1}, P, Q$ の組は無数 に存在する・たとえば， 


$$
K_{0}=\left[\begin{array}{l}
0 \\
0
\end{array}\right], \quad K_{1}=\left[\begin{array}{r}
1 \\
-1
\end{array}\right], \quad P=\left[\begin{array}{ll}
1 & 0 \\
0 & 1
\end{array}\right], \quad Q=\left[\begin{array}{ll}
2 & 0 \\
0 & 2
\end{array}\right]
$$

と選べば (4.7)，(4.8)式を満たすので，つぎのシステ ムはシステム $(4.3)$ の観測器の一つとなる.

$$
\begin{aligned}
\dot{z}(t)= & \left\{\left[\begin{array}{rr}
-1 & 0 \\
0 & -1
\end{array}\right]+u(t)\left[\begin{array}{rr}
0 & -1 \\
1 & 0
\end{array}\right]\right\} z(t) \\
& +\left\{\left[\begin{array}{l}
a_{02} \\
a_{03}
\end{array}\right]+u(t)\left[\begin{array}{l}
a_{12}-a_{01} \\
a_{13}+a_{01}
\end{array}\right]\right. \\
& \left.+u(t)^{2}\left[\begin{array}{c}
-a_{11} \\
a_{11}
\end{array}\right]\right\} y(t)+u(t)\left[\begin{array}{r}
1 \\
-1
\end{array}\right] \dot{y}(t)
\end{aligned}
$$

[例 2]

$$
\begin{aligned}
& \dot{x}(t)=\left[\begin{array}{c:rr}
\bar{A}_{011} & -2 & -1 \\
1 & -1 \\
\hdashline \bar{A}_{021} & 0 & 0 \\
\hdashline 0 & 0
\end{array}\right] x(t)+u(t)\left[\begin{array}{c:cc}
\bar{A}_{111} & 1 & 0 \\
\hdashline \bar{A}_{121} & 0 & 0 \\
\hdashline & 0 & 0
\end{array}\right] x(t) \\
& y(t)=\left[\begin{array}{ll:ll}
1 & 0 & 0 & 0 \\
0 & 1 & 0 & 0
\end{array}\right] x(t)
\end{aligned}
$$

このシステムに対して，まず文献 7) による観測器を 適用してみる.

$$
S=\left[\begin{array}{ll}
s_{11} & s_{12} \\
s_{21} & s_{22}
\end{array}\right], \quad P=\left[\begin{array}{ll}
p_{11} & p_{12} \\
p_{12} & p_{22}
\end{array}\right]\left(\begin{array}{c}
p_{11}, p_{22}>0 \\
p_{12}{ }^{2}<p_{11} p_{22}
\end{array}\right)
$$

とおけば，(4.2)式はつぎのようになる.

$$
P\left(S \bar{A}_{112}+\bar{A}_{122}\right)+\left(S \bar{A}_{112}+\bar{A}_{122}\right)^{T} P=\left[\begin{array}{cc}
2\left(p_{11} s_{11}+p_{12} s_{21}\right) & p_{11} s_{12}+p_{12}\left(s_{11}+s_{22}\right)+p_{22} s_{21} \\
p_{11} s_{12}+p_{12}\left(s_{11}+s_{22}\right)+p_{22} s_{21} & 2\left(p_{12} s_{12}+p_{22} s_{22}\right)
\end{array}\right]=0
$$

ゆえに（4.2)式が成立するためには，次式が満足され ねばならない。

$$
\begin{aligned}
& p_{11} s_{11}+p_{12} s_{21}=0 \\
& p_{12} s_{12}+p_{22} s_{22}=0 \\
& p_{11} s_{12}+p_{12}\left(s_{11}+s_{22}\right)+p_{22} s_{21}=0
\end{aligned}
$$

この(4.11)式を満たす $S, P$ に対して

$P\left(S \bar{A}_{012}+\bar{A}_{022}\right)+\left(S \bar{A}_{012}+\bar{A}_{022}\right)^{T} P$

$$
=-\left(p_{12} s_{11}+p_{22} s_{21}\right)\left[\begin{array}{ll}
1 & 1 \\
1 & 1
\end{array}\right]
$$

となる.したがって，(4.2)式を満たす $S, P$ は存在す るがそれらの $S, P$ に対して (4.1) 式を満たす正定対称 行列Qは存在しない.ゆえに文献 7) による観測器は 構成不可能である. つぎに文献 8）による観測器を適 用する。まず定理 1 の条件 (iii) より

$$
K_{1} \bar{A}_{112}=K_{1}=0
$$

となる。つぎに定理 1 の条件(ii)より

$$
\bar{A}_{122}-K_{1} \bar{A}_{012}-K_{0} \bar{A}_{112}=-K_{0}=0
$$

となり $K_{0}=K_{1}=0$ と決まる．とのとき

$$
\bar{A}_{022}-K_{0} \bar{A}_{012}=\bar{A}_{022}=\left[\begin{array}{ll}
0 & 0 \\
0 & 0
\end{array}\right]
$$

となり安定行列ではない.したがって，文献 8)によ る観測器屯構成不可能である。ここで本論文の観測器 を適用する。

$$
K_{0}=\left[\begin{array}{ll}
k_{011} & k_{012} \\
k_{021} & k_{022}
\end{array}\right], \quad K_{1}=\left[\begin{array}{ll}
k_{111} & k_{112} \\
k_{121} & k_{122}
\end{array}\right]
$$

とおけば，定理 2 の条件（i）（iii）はつぎのようにな る.

$$
\text { (i) } \begin{aligned}
P & {\left[\begin{array}{ll}
2 k_{011}-k_{012} & k_{011}+k_{012} \\
2 k_{021}-k_{022} & k_{021}+k_{022}
\end{array}\right] } \\
& +\left[\begin{array}{cc}
2 k_{011}-k_{012} & 2 k_{021}-k_{022} \\
k_{011}+k_{012} & k_{021}+k_{022}
\end{array}\right] P=-Q
\end{aligned}
$$

(ii) $P\left[\begin{array}{ll}2 k_{111}-k_{112}-k_{011} & k_{111}+k_{112}-k_{012} \\ 2 k_{121}-k_{122}-k_{021} & k_{121}+k_{122}-k_{022}\end{array}\right]$

$$
\begin{aligned}
& +\left[\begin{array}{cc}
2 k_{111}-k_{112}-k_{011} & 2 k_{121}-k_{122}-k_{021} \\
k_{111}+k_{112}-k_{012} & k_{121}+k_{122}-k_{022}
\end{array}\right] P \\
& =0
\end{aligned}
$$

（iii） $P\left[\begin{array}{ll}k_{111} & k_{112} \\ k_{121} & k_{122}\end{array}\right]+\left[\begin{array}{ll}k_{111} & k_{121} \\ k_{112} & k_{122}\end{array}\right] P=0$

この (4.12)〜 (4.14)式を満たす $K_{0}, K_{1}, P, Q$ の組は 無数に存在する.たとえば,

$$
\begin{aligned}
& K_{0}=\left[\begin{array}{rr}
-1 & -1 \\
0 & -1
\end{array}\right], \quad K_{1}=\left[\begin{array}{rr}
0 & 1 \\
-1 & 0
\end{array}\right], \quad P=\left[\begin{array}{ll}
1 & 0 \\
0 & 1
\end{array}\right], \\
& Q=\left[\begin{array}{ll}
2 & 1 \\
1 & 2
\end{array}\right]
\end{aligned}
$$

と選べば (4.12)〜 (4.14)式を満たすので，つぎのシス テムはシステム $(4.10)$ の観測器の一つとなる.

$$
\begin{aligned}
\dot{z}(t)= & \left\{\left[\begin{array}{rr}
-1 & -2 \\
1 & -1
\end{array}\right]+u(t)\left[\begin{array}{rr}
0 & 2 \\
-2 & 0
\end{array}\right]+u(t)^{2}\left[\begin{array}{rr}
0 & -1 \\
1 & 0
\end{array}\right]\right\} z(t) \\
& -\left\{\left[\begin{array}{rr}
-1 & -1 \\
0 & -1
\end{array}\right]+u(t)\left[\begin{array}{rr}
0 & 1 \\
-1 & 0
\end{array}\right]\right\} \\
& \cdot\left\{\bar{A}_{011}+u(t) \bar{A}_{111}\right\} y(t)+\left\{\bar{A}_{021}+u(t) \bar{A}_{121}\right\} y(t) \\
& +\left\{\left[\begin{array}{rr}
-1 & -1 \\
0 & -1
\end{array}\right]+u(t)\left[\begin{array}{rr}
0 & 1 \\
-1 & 0
\end{array}\right]\right\} \dot{y}(t)
\end{aligned}
$$

つぎの例 3 之例 4 は文献 6) で扱われたすのである. しかし, 例 3 に対して与えられた観測器は $u(t)<3, v t$ のときに大域的漸近安定になるのみであり，また例 4 には安定な観測器は与えられていない吕. 本論文の方 法によって安定な観測器を構成する.

[例 3]

$$
\begin{aligned}
& \dot{x}(t)=\left[\begin{array}{rr}
2 & 3 \\
0 & -1
\end{array}\right] x(t)+u(t)\left[\begin{array}{ll}
1 & 0 \\
0 & 1
\end{array}\right] x(t)+\left[\begin{array}{r}
1 \\
-1
\end{array}\right] u(t) \\
& y(t)=\left[\begin{array}{ll}
1 & 0
\end{array}\right] x(t)
\end{aligned}
$$

$\bar{A}_{112}=0$ であるから定理 2 の条件（iii）は常に満足され 
ている。また，

$$
\begin{aligned}
& \bar{A}_{022}-K_{0} \bar{A}_{012}=-1-3 K_{0} \\
& \bar{A}_{122}-K_{1} \bar{A}_{012}-K_{0} \bar{A}_{112}=1-3 K_{1}
\end{aligned}
$$

であるから， $K_{0}>-1 / 3, \quad K_{1}=1 / 3$ と選べば定理 2 の 条件 (i ) (ii)を満たす. ここで，Ko をパラメータと して観測器を構成するとつぎのシステムとなる.

$$
\begin{aligned}
\dot{z}(t)= & \left(-1-3 K_{0}\right) z(t) \\
& -\left(K_{0}-\frac{1}{3} u(t)\right)(u(t)+2 y(t)+u(t) y(t)) \\
& +\left(K_{0}+\frac{1}{3} u(t)\right) \dot{y}(t)
\end{aligned}
$$

いま, $e(t)=\bar{x}_{2}(t)-z(t)$ として䛊差方程式をつくると

$$
\dot{e}(t)=\left(-1-3 K_{0}\right) e(t)
$$

したがって， $K_{0}(>-1 / 3)$ の值を変えるととにより， 任意の速さで推定䛊差を零に収束させることができ る.

\section{[例 4]}

ボルテラモデルで宿主数 $(H)$ だけが観測できると きに，寄生動物数 $(P)$ を推定することを考える。す なわち，つぎのシステムに対する観測器を構成するこ とである.

$$
\begin{aligned}
& {\left[\begin{array}{c}
\dot{H}(t) \\
\dot{P}(t)
\end{array}\right]=\left[\begin{array}{cc}
a_{1} & 0 \\
0 & -a_{2}
\end{array}\right]\left[\begin{array}{l}
H(t) \\
P(t)
\end{array}\right]+H(t)\left[\begin{array}{cc}
0 & -b_{1} \\
0 & b_{2}
\end{array}\right]\left[\begin{array}{l}
H(t) \\
P(t)
\end{array}\right]} \\
& y(t)=\left[\begin{array}{ll}
1 & 0
\end{array}\right]\left[\begin{array}{l}
H(t) \\
P(t)
\end{array}\right] \quad a_{1}, a_{2}, b_{1}, b_{2}>0
\end{aligned}
$$

$\bar{A}_{112}=-b_{1}(<0)$ であるから定理 2 の条件（iii）より $K_{1}$ =0 と決まる. また，

$$
\begin{aligned}
& \bar{A}_{022}-K_{0} \bar{A}_{012}=-a_{2} \quad(<0) \\
& \bar{A}_{122}-K_{0} \bar{A}_{112}=b_{2}+K_{0} b_{1}
\end{aligned}
$$

であるから， $K_{0}=-b_{2} / b_{1}, K_{1}=0$ とすれば定理 2 の 条件 ( $\mathrm{i}) \sim(\mathrm{ii})$ を満たす $P, Q$ が存在する. したがっ て観測器はつぎのように構成できる.

$$
\dot{z}(t)=-a_{2} z(t)+\frac{b_{2}}{b_{1}}\left(a_{1} y(t)-\dot{y}(t)\right)
$$

このとき観測器の収束速度は次式で評価される。

$$
|P(t)-z(t)| \leqq|P(0)-z(0)| \exp \left(-a_{2} t\right) \quad \text { (4. 20) }
$$

また，とのシステムは $K_{1}=0$ のとき観測器が存在す るので, $z^{*}(t)=z(t)-K_{0} y(t)$ の変換により出力 $y(t)$ の 1 階微分の項を消去できる. 定理 3 により出力の 1 階微分を含まない観測器はつぎのようになる。

$$
\dot{z}^{*}(t)=-a_{2} z^{*}(t)+\frac{b_{2}}{b_{1}}\left(a_{1}+a_{2}\right) y(t)
$$

$$
w^{*}(t)=z^{*}(t)-\frac{b_{2}}{b_{1}} y(t)
$$

\section{5. 結 誩}

本論文では，双線形システムの観測器の新しい構成 法を報告した.すなわち，双線形システムの出力は常 に 1 階微分可能であるという事実に注目して，入出力 および出力の 1 階微分の情報を用いた観测器の構成法 を考察した．観测俁差が入力に無関係に大域的漸近安 定になるという視点により，乙れまでのものより広い クラスのシステムに対して簡単な構造の観測器が構成 可能となったままたり事実をいくつかの例によって 示した.

なお出力の微分值を用いなくてもよい観測器が構成 できる条件も明確な形で与えた．定理 2 の条件のみし か満たしえないときには，観測器を構成するのに出力 の微分情報が必要であり，またそれが得られる場合に は本文で述べたように観測器は簡単な形で与えられ る. 出力の微分情報が許されない場合には本論文の構 成法は適用できず，その場合には文献 1) などを適用 することになる。しかし，入力に依存する行列方程式 をオンラインで解かなくてはならなくなり，現実には そのような観測器は構成されえないと考えられる。

最後に日頃ご討論頂く中村嘉平教授に感謝します。

\section{参 考 文 献}

1) G. W. Johnson: A Deterministic Theory of Estimation and Control, IEEE Trans. on Automatic Control, AC-14, 380/384 (1969)

2) 古荘：双線形系に対するオブザーバ，第 17 回自動制御 連合講演会前刷, 133/134 (1974)

3) 原, 古田: 双線形系の状態観測器, 計測自動制御学会論 文集，12-6，625/631 (1976)

4) S. Hara and K. Furuta: Minimal Order State Observers for Bilinear Systems, Int. J. on Control, 24, 705/718 (1976)

5).小林, 示村：双線形システムのオブザーバに関する一考 察, Mathematical Systems Theory シンポジウム資 料, 35/40 (1976)

r6）林，坂口，宗像：Luenberger オブザーバの双線形系へ の拡張とその応用，第 6 回制御理論シンポジウム資料 (1977)

7) Y. Funahashi: Stable State Estimator for Bilinear Systems, St. Louis Meeting of US-Japan Cooperative Research, Aug. (1977)

8) Y. Funahashi: A Class of State Observers for Bilinear Systems, International Journal of System Science, to appear 